\title{
Prevalence of Chlamydia infection among teens in Mississippi 2015-2019: the need for a comprehensive sex education
}

\author{
Praise Ebimaye Tangbe*, Border-ere Fiemotonghan**, Temiloluwa Ogundeyi*** \\ *Department of Behavioral and Environmental Health, Jackson State University \\ **Department of Public Policy and Administration, Jackson State University \\ ****Department of Behavioral and Environmental Health, Jackson State University \\ DOI: 10.29322/IJSRP.11.08.2021.p11622 \\ http://dx.doi.org/10.29322/IJSRP.11.08.2021.p11622
}

\begin{abstract}
Background: The increasing rate of Chlamydia genital infection among teens in Mississippi remains a public health concern.

Aims and objectives: This study aims to examine prevalence of Chlamydia trachomatis and the usage of condom according to age, race, and grade.

Methods: This study was conducted using existing data from Mississippi State Department of Health (MSDH) and a crosssectional study data from Youth risk Behavior Survey System (YRSS). MSDH Data trends on Sexually transmitted diseases (STD) and Human Immunodeficiency Virus (HIV) between 2015-2019 were assessed to examine the prevalence of Chlamydia among ages 10-19 in Mississippi. Also, YBRSS 2019 data were used to determine condom use, by identifying the socio-demographics of students in $9^{\text {th }}$ to $12^{\text {th }}$ grade.

Results: Black teenagers $(58 \%)$ have a higher rate of Chlamydia infections than White $(12 \%)$ and Hispanic $(0.2 \%)$ teenagers over the years. There is an increasing trend of Chlamydia infections among teenagers between the age of 1519 years when compared to those between 10-14 years. Chlamydia rate is found to be higher in females than males across all races. In addition, Male $(59.9 \%)$ are more likely to use condom during intercourse than females (36.8\%).

Conclusions: Chlamydia trachomatis is highly prevalent among teenagers between ages 15-19 in Mississippi, most especially within the black community than in the United States overall. There is an urgent need for sexually transmitted diseases programs and interventions for teenagers in Mississippi. Also, teenagers need to have access to accurate and comprehensive sex education programs.
\end{abstract}

Index Terms- Chlamydia trachomatis, Condom Use, Teenagers, Black

\section{INTRODUCTION}

Chlamydia Trachomatis genital infection is among the most prevalent of all sexually transmitted infections (STIs) in the United States, especially among teenage women [1]. It is a sexually transmitted bacterial infection that causes cervicitis in females and urethritis in males. Chlamydia can result in pelvic inflammatory disease, which causes chronic pelvic pain, infertility, and ectopic pregnancy [1]. It is primarily transmitted by sexual intercourse; the incubation period ranges from 7 to 24 days or longer [2]. Pregnant women who are infected can transfer the infection to the infant during delivery, which may result in ophthalmia neonatorum. This can lead to pneumonia or an eye infection, and most likely preterm birth [1]. CDC recommends annual chlamydia screening for all women younger than 25 years of age because of the high burden of pelvic inflammatory disease and risks associated with infection. During 2000-2011, the prevalence rate of chlamydia infection increased from 251.4 to 453.4 cases per 100,000 population in the United States [1]. In 2016, the chlamydial infection rate increased by $4.7 \%$, from 475.0 to 497.3 cases per 100,000 population [1]. Also, the Sexually Transmitted Disease Surveillance reported that the prevalence rate of Chlamydia increased by 2.8 percent in year 2019 , which is 552.8 cases per 100,000 population [1]. Additionally, report showed that in the year 2018, ages 15 to 19 were infected by Chlamydia at a rate of 2,110.6 cases per 100,000 population [3].

STDs such as chlamydia contribute tremendously to health and economic burdens on individuals [4]. STDs infections in populations can lead to direct medical costs to individuals such as inpatient and outpatient care, which is associated with screening, detection, and treatment of chlamydia infection [5]. Also, the indirect cost can lead to longterm loss of human capital in the society due to low productivity and chlamydia-related morbidities that may result in time off from work [6]. Reports show an estimation of $\$ 6.5$ billion is spent for a direct medical cost for treating young people with STDs annually in the United States, excluding the cost for HIV/AIDS [6]. According to [1], limited resources make it difficult for timely testing and treatment of chlamydia infection. In the past years, more than half of state and local STDs funding have been cut, thus, leading to reduced clinic hours, staff layoffs, and increased co-pays that will create barriers to access quality treatment [6].

High-risk sexual behavior such as unprotected sex put individuals at risk for STDs [7]. According to [7], the use of condom during sexual intercourse is low among U.S youths. Even though when individuals use condoms, they are often used incorrectly or inconsistently; thus, leading to reduction in 
the effectiveness of the condom [8]. Report showed that between $2011-2015,23.8 \%$ of women and $33.7 \%$ of men aged 15-44 reported using condom during their last sexual intercourse [7]. Also, about $7 \%$ of women who used condom during their last sexual intercourse stated that the condom broke or fell off during sexual intercourse [7].

Mississippi (MS) ranked third in the United States for chlamydia infection rates [1]. In Mississippi, the rate of chlamydial infection increased from 580.5 in 2015 to 672.1 per 100,000 population in 2016 compared to the national rate of 497.3 [8]. There is a huge disparity in the prevalence of Chlamydial infection for the past 5 years [9] [10]. In 2010, the rates of chlamydia infection for females were 2.75 times than the rate of males [2], [11], [12]. In addition, report showed that there was a decrease rate of condom usage from 2007 to 2019 among Mississippi high school students [2].

An explanation for this could essentially be attributed to the fact that the governing party is conservative, and the state of Mississippi is identified as a bible belt state. States play a significant role in the implementation of public policies and laws. There was no sex education policy in the state of Mississippi until the year 2011 when the HB 999 was passed [13]. Schools that taught sex education were required to teach abstinence-only or abstinence-plus curricula [13]. The law stated that instruction and demonstration on the application and use of condoms shall not be included in the curriculum. Because of the lack of statutory requirements, education standards, and curriculum guidelines to teach sex education preceding 2011, most of the students did not get essential sexual health information they needed to make the right decisions concerning their sexual behavior [13] [14] [15].

\section{EXISTING PROGRAM}

Government partners and nonprofits funded the mandate that allows school districts to implement the "Creating Healthy and Responsible Teens" (CHART) program. CHART compels public school districts to increase the adoption and implementation of the state's sex education law [13], CHART provides resources and technical assistance to school districts free of charge through the personal responsibility education program (PREP) grants [13]. The MS state's sex education policy is restricted to just abstinence-only; thus, programs have been ineffective in decreasing STDs among teenagers [13]. According to [13], teens that complete abstinence-only programs are as likely to engage in sexual intercourse and less likely to use protection. This is because the abstinence-only curriculum does not include the instruction and demonstration of condom use [14], [15]. CHART adopted the abstinence-plus policy to help reduce teen births and STD rates by adopting medically accurate, evidence-based, and age-appropriate sex education [13]. Furthermore, abstinence-plus discusses other contraceptives, causes, and effects of sexually transmitted diseases, and the prevention of sexually transmitted diseases [13], [14]. Also, school boards have the option through a majority vote to teach sex education that did not stress abstinence-only [11]. The assessment of STDs such as Chlamydia at the state level is very important to impact STDs prevention programs and decisions regarding policy amendment in the state of Mississippi. Several studies have

This publication is licensed under Creative Commons Attribution CC BY.

http://dx.doi.org/10.29322/IJSRP.11.08.2021.p11622 been conducted on the prevalence of Chlamydia infection in the US, yet limited studies have been done on the trends in prevalence among teens in MS.

The aim of this study is to: 1) examine the trends and prevalence of chlamydia trachomatis infections from 2015 to 2019 and 2) examine the demographic characteristics of condom use during sexual intercourse among teens in Mississippi, U.S.

\section{MATERIALS AND METHODS}

STD/HIV Data and Statistics from the 2015-2019 Mississippi State Department of Health (MSDH) and 2019 Mississippi High School Youth Risk Behavior Survey System (YRBSS) were used for the analyses. STD/HIV Data and Statistics data of 2015-2019 were analyzed to determine the trends in Chlamydia prevalence among ages 10-19, race, and sex. The YBRSS 2019 data were used to measure the prevalence of condom use by sex, race, and grade. YRBSS is a cross-sectional study survey used to monitor health outcomes and risk behavioral change among high school students in the United States [16]. The 2019 YRBSS sampling consist of all public and nonpublic schools with students from $9^{\text {th }}$ to $12^{\text {th }}$ grade. The YRBSS sample was determined using a three-stage probability design to produce a representative sample of students [16]. In addition, the estimated prevalence of Chlamydia infection rate among participants were adjusted based on ages 10-19, race and sex from the 2015-2019 STD/HIV Data and Statistics. Univariate t-test statistical analysis was conducted to determine the percentage differences in groups and frequency distribution.

\section{RESULT}

Table 1 showed the prevalence of Chlamydia based on race revealed that Blacks/African Americans (58\%) had higher rate of Chlamydia than White $(12 \%)$, and Hispanic $(0.2 \%)$ teens. According to STD/HIV Data and Statistics result, Black teens had a rate of $58 \%$ compared to White with a rate of $12 \%$, Hispanic (0.2), Others (1.2\%) and Unknown (29\%) in 2015; in 2016 , Black teens had a rate of $55.1 \%$ compared to White with $11.5 \%$, Hispanics $(0.3 \%)$, Others $(1.2 \%)$ and Unknown $(32 \%)$ (Table 1). While in 2017, Black had a rate of $53.7 \%$ compared to White with a rate of $12.1 \%$, Hispanics $(0.2 \%)$, Others $(2.1 \%)$ and Unknown (31.9\%). In the year 2018 and 2019, Black had a rate of Chlamydia of $48.6 \%$ and $47.5 \%$ compared to White teens with a rate of $11.1 \%$ and $11.6 \%$, Hispanics $(0.2 \%$ and $0.4 \%)$, Others $(0.4 \%$ and $0.8 \%)$ and Unknown ( $40 \%$ and $40 \%)$ respectively (Table 1). In addition, the prevalence of Chlamydia based on sex showed that females had higher Chlamydia infection rate than males from 2015 - 2019 (Table 1). Figure 1 shows the trends in increase prevalence rate of Chlamydia infection among ages 10-14 and 15-19 years. Participants aged 15-19 years had higher prevalence rate than those aged 10-14years. The YRBSS result showed that males used condom during their last sex intercourse than females (Table 2). The prevalence of condom use during last sexual intercourse for males is $59.9 \%$ compared to females $(36.8 \%)$ (Table 2). 
Table 1: Prevalence of Chlamydia among ages 10 -19 by race and sex in Mississippi, STD/HIV Data and Statistics, 2015-2019.

\begin{tabular}{|c|c|c|c|c|c|}
\hline Year: & 2015 & 2016 & 2017 & 2018 & 2019 \\
\hline \multirow[t]{2}{*}{ Total } & 5,814 & 6734 & 7083 & 7400 & 8272 \\
\hline & $\%($ total $n)$ & $\%($ total $n)$ & $\%($ total n) & $\%($ total n) & $\%($ total $n)$ \\
\hline \multicolumn{6}{|l|}{ Race } \\
\hline \multicolumn{6}{|l|}{ Black/AA } \\
\hline Female & $43.2 \%(2510)$ & $41 \%(2737)$ & $39.4 \%(2793)$ & $36.1 \%(2674)$ & $35.2 \%(2910)$ \\
\hline Male & $14.4 \%(839)$ & $14.4 \%$ (973) & $14.2 \%(1011)$ & $12.5 \%(925)$ & $12.3 \%(1019)$ \\
\hline Total (\%) & $58 \%$ & $55.1 \%$ & $53.7 \%$ & $48.6 \%$ & $47.5 \%$ \\
\hline \multicolumn{6}{|l|}{ White } \\
\hline Female & $10 \%(575)$ & $10 \%(665)$ & $10.4 \%$ (734) & $10 \%(727)$ & $10 \%(809)$ \\
\hline Male & $2.1 \%(124)$ & $1.5 \%(107)$ & $2 \%(125)$ & $1.3 \%(98)$ & $1.8 \%(149)$ \\
\hline Total (\%) & $12 \%$ & $11.5 \%$ & $12.1 \%$ & $11.1 \%$ & $11.6 \%$ \\
\hline \multicolumn{6}{|l|}{ Hispanic } \\
\hline Female & N/A (8) & N/A (16) & N/A (10) & N/A (14) & N/A (26) \\
\hline Male & N/A (1) & N/A (2) & N/A (3) & N/A (1) & N/A (3) \\
\hline Total (\%) & $0.2 \%$ & $0.3 \%$ & $0.2 \%$ & $0.2 \%$ & $0.40 \%$ \\
\hline \multicolumn{6}{|l|}{ Other } \\
\hline Female & N/A (57) & N/A (62) & $2 \%(117)$ & N/A (24) & N/A (47) \\
\hline Male & N/A (14) & N/A (17) & N/A (29) & N/A (8) & N/A (16) \\
\hline Total (\%) & $1.2 \%$ & $1.2 \%$ & $2.1 \%$ & $0.4 \%$ & $0.8 \%$ \\
\hline \multicolumn{6}{|l|}{ Unknown } \\
\hline Female & $24.1 \%(1402)$ & $26 \%(1746)$ & $25.4 \%(1797)$ & $30.1 \%(2227)$ & $31 \%(2544)$ \\
\hline Male & $5 \%(284)$ & $6.1 \%(409)$ & $7 \%(464)$ & $9.5 \%$ (702) & $9.1 \%(749)$ \\
\hline Total $(\%)$ & $29 \%$ & $32 \%$ & $31.9 \%$ & $40 \%$ & $40 \%$ \\
\hline
\end{tabular}

Abbreviation: cell size; N/A < 100 respondents for the subgroup. Source: STD/HIV Data and Statistics, 2015-2019. 
Prevalence of Chlamydia among teens in MS by age

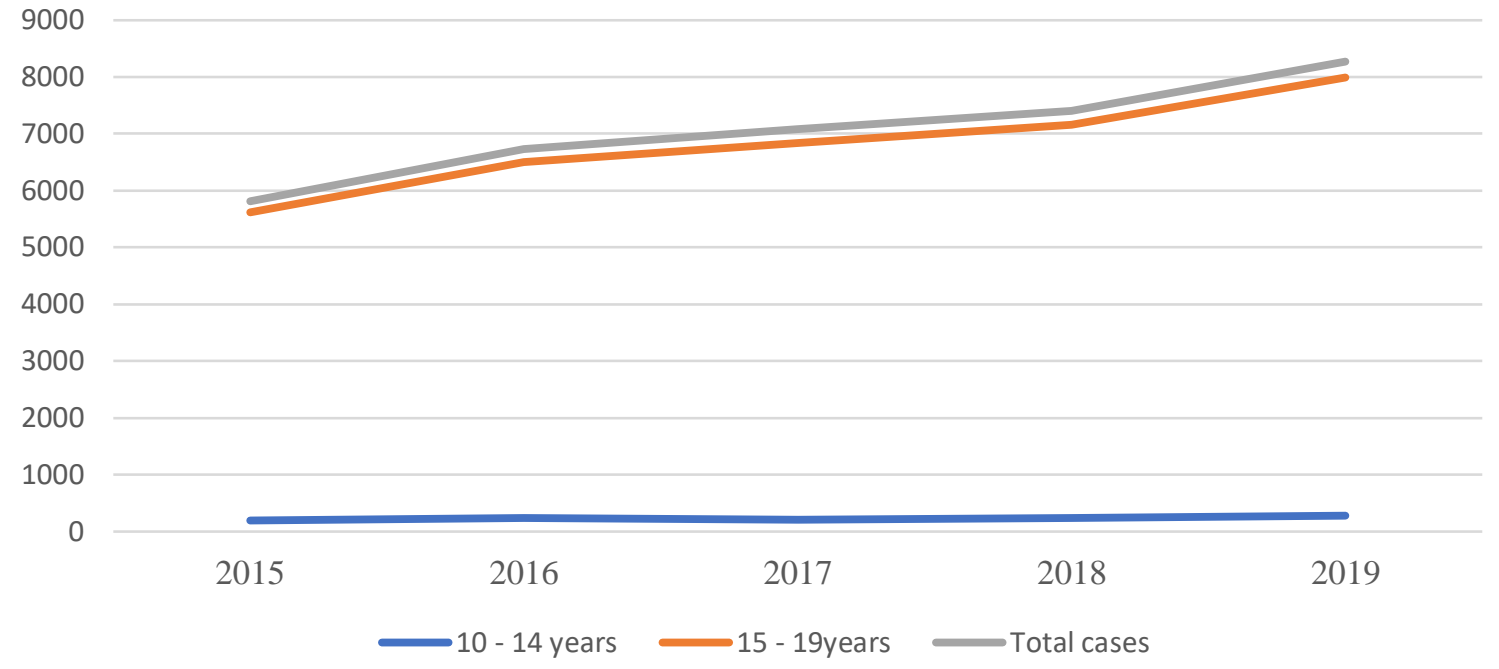

Figure 1. Prevalence of Chlamydia infections among teens in Mississippi by age, STD/HIV Data and Statistics, 2015-2019.

Table 2: Prevalence of High school students in Mississippi who used a condom during last sexual intercourse*

\begin{tabular}{|c|c|c|c|c|c|c|}
\hline & \multicolumn{2}{|l|}{ Total } & \multicolumn{2}{|l|}{ Female } & \multicolumn{2}{|l|}{ Male } \\
\hline & $\begin{array}{l}\text { Total percentage ( } 95 \% \\
\text { CL) }\end{array}$ & $\begin{array}{l}\text { Total } \\
(\mathrm{n})\end{array}$ & Percentage $(95 \% \mathrm{CI})$ & Total (n) & $\begin{array}{l}\text { Percentage } \\
(95 \% \mathrm{CI})\end{array}$ & Total $(\mathrm{N})$ \\
\hline Total & $48.4(43.2-53.6)$ & $381 \dagger$ & $36.8(29.8-44.5)$ & 191 & $59.9(51.0-68.2)$ & 190 \\
\hline \multicolumn{7}{|l|}{ Race } \\
\hline Black/AA & $51.6(45.0-58.1)$ & $157 \dagger$ & N/A & 80 & N/A & 77 \\
\hline White & $44.5(35.1-54.3)$ & $175 \dagger$ & N/A & 86 & N/A & 89 \\
\hline Hispanic & N/A & $20 \dagger$ & N/A & 10 & N/A & 10 \\
\hline \multicolumn{7}{|l|}{ Grade } \\
\hline 12th & $43.0(33.4-53.1)$ & $153 \dagger$ & N/A & 85 & N/A & 68 \\
\hline 11th & N/A & $85 \dagger$ & N/A & 49 & N/A & 36 \\
\hline 10th & N/A & $79 \dagger$ & N/A & 36 & N/A & 43 \\
\hline 9th & N/A & $62 \dagger$ & N/A & 21 & N/A & 41 \\
\hline
\end{tabular}

Abbreviation: $\uparrow$ Percentage, confidence interval, cell size; N/A $<100$ respondents for the subgroup. Source: Youth Risk Behavioral Surveillance System (YRBSS), 2019.

*Among students who were currently sexually active) Mississippi, High School Youth Risk Behavior Survey, 2019

Prevalence of condom usage among students were analyzed using the YRBSS 2019 data, result showed that $59.9 \%$ of males use condom during their last sexual intercourse compared to females with a rate of $36.8 \%$.

\section{DISCUSSION}

Chlamydia genital infections could lead to pelvic inflammatory disease, infertility, and chronic pelvic pain in women, especially if left untreated [17]. This study examined the prevalence of Chlamydia genital infections from 2015 to 2019 and condom usage among teens in MS. The results show a significant racial disparity in chlamydia infection in Mississippi, with a notable increase in infection rate among Black youths from ages 15-19. In addition, our result indicates This publication is licensed under Creative Commons Attribution CC BY. http://dx.doi.org/10.29322/IJSRP.11.08.2021.p11622 that the infection rate of Black female youths is significantly higher than Black males. It is evident that Black females still rank the highest in Chlamydia infection rate in the United States and Mississippi. However, there is an $8 \%$ decline in infection rates in Mississippi since 2015 (43.2\% in 2015 vs. $35.2 \%$ in 2019). Although we see a slight reduction in the infection rates among Black females, the number of infection rates in Mississippi is still on the rise. 
As predicted, the findings of this study are consistent with other literature that shows the prevalence of chlamydia infection among Blacks/African Americans and the existence of racial/age disparity in the United States [18], [19], [20], [21], [22]. Supporting our findings, in 2018, [18], [19] reported that the national cases of chlamydia among black females (15-19) in the United States were 4.5 times higher when compared to white females. Similar racial disparities exist for Black males; the infection rate among Black men (15-19) was 9.1 times the rate compared to white males [18]. According to the report presented by [18], there were 1,411.1 Black females infected with chlamydia in 2018 and 952.3 infected males per 100,000 population. This result supports our findings [Table 1] that Black females in Mississippi have a higher infection rate than their male counterparts and other groups. Furthermore, [Table 1] shows that persons from 15-19 are more at risk for chlamydia infection. The report from [23] is consistent with our findings; according to [23], chlamydia is more prevalent among adolescents as $61 \%$ of diagnosed cases were persons from 15 24 years [23].

The infection rate among Black adolescent females in Mississippi declined by $8 \%$, but the state average increased by $11 \%$ (2015-2019). The trends in Mississippi and the United States are consistent. Chlamydia is more prevalent among Black Americans, with Black females being more at risk. The racial/sex disparity of chlamydia infection rate might be connected to the significant difference in condom use in males and females. Our results [8] show that $59.9 \%$ of males used condoms during last intercourse than $36.8 \%$ of women. These results indicate that males are approximately 1.6 times more likely to use condoms during intercourse than their female counterparts. These results are consistent with the findings from [8]. According to [8], $24.7 \%$ of men used condoms compared to $18.4 \%$ of women. Also, $79.1 \%$ of adolescent men (10-19) reported using a condom in the last ten vaginal intercourses compared to $58.1 \%$ of women [8]. Other research $[7,8,24]$ supports our findings that the use of condoms by females is significantly lower compared to males; therefore, it is important to explore factors that might be responsible for this disparity.

Despite the relevance and contributions of this research, it is important to note the limitations in our analysis. First, the YBRSS 2019 data used to measure the prevalence of condom use might indicate a possibility of inaccuracy due to self-report bias. In addition, our study only explores the lack of condom use as a risk factor that might contribute to higher infection rates. Exploring other sexual risk behaviors may provide significant insights into the unbalanced racial/sex ratio in Mississippi and the Black/African American community. Second, this study did not consider social and economic factors contributing to the lower rate of condom use among females. Furthermore, the report on condom use by YRBSS consisted of high school students; while this is a good representation of adolescents, our study ignores other groups of adolescents in Mississippi. Regardless of these limitations, this study adequately reports the trends of Chlamydia infection across racial and gender lines in Mississippi.

\section{CONCLUSION}

This publication is licensed under Creative Commons Attribution CC BY. http://dx.doi.org/10.29322/IJSRP.11.08.2021.p11622
This study shows an increasing prevalence of chlamydia infections among teens in MS and poor condom use especially among females. There should be an amendment of the state policy that can inform and educate communities that bear STD burdens, which will potentially reduce risky sexual behaviors among teens in Mississippi. Public health officials should involve policymakers in STDs prevention interventions to promote the implementation of comprehensive sex education in Mississippi school districts.

\section{REFERENCES}

1. Centers for Diseases and Prevention Control. 2016 sexually transmitted diseases surveillance. Retrieved from https://www.cdc.gov/std/stats16/chlamydia.htm

2. Mississippi State Department of Health. STD/HIV data and statistic: Reported cases of Chlamydia 2015-2019. Retrieved from https://msdh.ms.gov/msdhsite/ static/31,0,150,807.html

3. Diesel J, Peterson A, Peterman T. Reported chlamydia and gonorrhea are decreasing among young Black women: Good news or bad news? A narrative review. Sexually Transmitted Diseases. 2021 Jun 5.

4. National HIV/AIDS Strategy. Community action plan framework. Retrieved from https://www.hiv.gov/federal-response/national-hivaids-strategy/strategy-in-action

5. Ford JV, Ivankovich MB, Douglas Jr JM, Hook III EW, Barclay L, Elders J, Satcher D, Coleman E. The need to promote sexual health in America: a new vision for public health action. Sexually Transmitted Diseases. 2017 Oct 1;44(10):579-85.

6. Chesson HW, Blandford JM, Gift TL, Tao G, Irwin KL. The estimated direct medical cost of sexually transmitted diseases among American youth, 2000. Perspectives on sexual and reproductive health. $2004 \mathrm{Jan} ; 36(1): 11-9$.

7. Copen CE. Condom Use During Sexual Intercourse Among Women and Men Aged 15-44 in the United States: 2011-2015 National Survey of Family Growth. National health statistics reports. 2017 Aug 1(105):1-8.

8. National Survey of Family Growth. National health statistics reports, (105), 1-18.

9. Reece M, Herbenick D, Schick V, Sanders SA, Dodge B, Fortenberry JD. Condom use rates in a national probability sample of males and females ages 14 to 94 in the United States. The journal of sexual medicine. 2010 Oct; 7: 266-76.

10. County Health Rankings and Roadmaps. Sexually transmitted infections. Retrieved from http://www.countyhealthrankings.org/app/mississippi/2018/measur e/factors/45/map

11. Centers for Disease Control and Prevention. 1991-2019 High School Youth Risk Behavior Survey Data. Available at http://yrbsexplorer.services.cdc.gov/. Accessed on [date].

12. National Center for HIV/AIDS, Viral Hepatitis, STD, and TB Prevention. Trends in the prevalence of sexual behavior and HIV testing National YRBS: 1991-2015. Available from: http://www. cdc.gov/healthyyouth/data/yrbs/pdf/ trends/2015_us_sexual_trend_yrbs.pdf.

13. Kreisel KM, Weston EJ, Cyr SB, Spicknall IH. Estimates of the prevalence and incidence of chlamydia and gonorrhea among US men and women, 2018. Sexually Transmitted Diseases. $2021 \mathrm{Apr}$ 1;48(4):222-31.

14. Teen Health Mississippi. Policy and advocacy. Retrieved from https://teenhealthms.org/policy-and-advocacy/

15. Barton, K., Castro-Crist, A., \& Quiroz, L. Lubbock health community: "Sex ED wanted. Retrieved from https://www.ttuhub.net/2016/10/lubbock-health-community-sexed-wanted/

\section{.} . 
16. Leichliter JS, Seiler N, Wohlfeiler D. STD prevention policies in the United States: Evidence and opportunities. Sexually transmitted diseases. 2016 Feb;43(2 Suppl 1): S113.

17. Underwood JM, Brener N, Thornton J, Harris WA, Bryan LN, Shanklin SL, Deputy N, Roberts AM, Queen B, Chyen D, Whittle L. Overview and methods for the youth risk behavior surveillance system-United States, 2019. MMWR supplements. 2020 Aug 21;69(1):1.

18. Healthy People 2030. Sexually Transmitted Infections. Available at: https://health.gov/healthypeople/objectives-and-data/browseobjectives/sexually-transmitted-infections/increase-proportionsexually-active-female-adolescents-and-young-women-who-getscreened-chlamydia-sti-01

19. "Health Disparities in HIV/AIDS, Viral Hepatitis, STDs, and TB." Centers for Disease Control and Prevention, Centers for Disease Control and Prevention, 14 Sept. 2020, www.cdc.gov/nchhstp/healthdisparities/africanamericans.html.

20. Chambers LC, Khosropour CM, Katz DA, Dombrowski JC, Manhart LE, Golden MR. Racial/ethnic disparities in the lifetime risk of Chlamydia trachomatis diagnosis and adverse reproductive health outcomes among women in King County, Washington. Clinical Infectious Diseases. 2018 Aug 1;67(4):593-9.

21. "CDC - Chlamydia Statistics." Centers for Disease Control and Prevention, Centers for Disease Control and Prevention, 5 Apr. 2021, www.cdc.gov/std/chlamydia/stats.htm.

22. Adimora AA, Schoenbach VJ. Social context, sexual networks, and racial disparities in rates of sexually transmitted infections. The Journal of infectious diseases. 2005 Feb 1;191(Supplement_1): S115-22.

23. National Overview - Sexually Transmitted Disease Surveillance, 2019 (cdc.gov)

24. Condom and Contraceptive Use Among Sexually Active High School Students - Youth Risk Behavior Survey, United States, 2019 | MMWR (cdc.gov)

25. African American women and sexually transmitted infections: The contextual influence of unbalanced sex ratios and individual risk behaviors (nih.gov)

\section{AUTHORS}

First Author - Praise Ebimaye Tangbe, MPH, Jackson State University, praise.tangbe@gmail.com Second Author - Border-ere Fiemotonghan, MA, Jackson State University, excelizzy@gmail.com Third Author - Temiloluwa Ogundeyi, MPH, Jackson State University, ogundeyitemiloluwa@gmail.com Corresponding author: - Praise Ebimaye Tangbe, MPH, Jackson State University, praise.tangbe@gmail.com, 2564689495 